\section{The dermatologic manifestations of COVID-19: a mini-review}

\author{
Sabah Alharazy* \\ Independent Researcher, Malaysia
}

\begin{abstract}
Severe acute respiratory syndrome coronavirus 2 (SARS-CoV-2), was identified in Wuhan, China, and caused coronavirus disease-19 (COVID-19), which is still a global pandemic. Dermatologic manifestations have increasingly been identified as significant extrapulmonary manifestations of COVID-19. The dermatologic manifestations associated with COVID-19 infection reported to date include maculopapular rash, vesicular lesions, urticaria-like lesions, and chilblain-like lesions. Knowledge of dermatologic manifestations of COVID-19 may be essential for early diagnosis and a better prognosis in COVID-19 patients. This review summarizes the current understanding of common COVID-19-associated dermatologic manifestations.
\end{abstract}

\section{Introduction}

Severe acute respiratory syndrome coronavirus 2 (SARSCoV-2) that caused coronavirus disease-19 (COVID-19) was declared as a pandemic by the world health organization (WHO) on March, 2020 [1].

The most common clinical manifestations of COVID-19 at onset are fever, cough, and fatigue [2,3]. Although COVID-19 is predominantly a respiratory disease, it can affect multiple organs including cardiovascular, renal, hepatic, gastrointestinal, neurologic, ocular, and dermatologic systems [4].

Knowledge of dermatologic manifestations associated with COVID-19 may be vital to early diagnosis and lead to probable better prognosis in COVID-19 patients [5]. In a systematic review including 1,847 patients with confirmed COVID-19, the overall prevalence of dermatologic manifestations in COVID-19 patients was $5.95 \%, 6$ with a range from $0.2 \%$ up to $20.4 \%$ in different studies [6-8].

The dermatologic changes reported in COVID-19 infection can be classified as either inflammatory exanthems or vascular lesions $[5,9]$. Inflammatory exanthems in COVID-19 infection can manifest as maculopapular, urticarial, vesicular, or Multisystem Inflammatory Syndrome in Children (MIS-C) rash [5] while vascular lesions are classified as pseudochilblain chilblain-like, petechiae/purpura, or livedoid lesions [5,9]. Inflammatory lesions often occur early during the disease and may sometimes occur before systemic infectious manifestations, while vascular lesions occur later in the disease course of COVID-19, usually several days

\section{More Information}

*Address for Correspondence: Sabah Alharazy, Independent Researcher, 33000, Kuala Kangsar, Perak, Malaysia,

Email: sabah_alharazy@yahoo.co.uk

Submitted: August 14, 2021

Approved: August 26, 2021

Published: August 27, 2021

How to cite this article: Alharazy S. The dermatologic manifestations of COVID-19: a mini-review. Ann Proteom Bioinform. 2021; 5: 042-048.

DOI: 10.29328/journal.apb.1001015

ORCiD: orcid.org/0000-0002-1183-089X

Copyright: @ 2021 Alharazy S. This is an open access article distributed under the Creative Commons Attribution License, which permits unrestricted use, distribution, and reproduction in any medium, provided the original work is properly cited.

Keywords: Dermatologic; COVID-19; SARSCoV-2; Maculopapular rash; Vesicular lesions; Urticaria-like lesions; Chilblain-like lesions

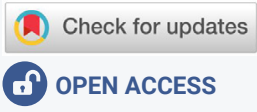

after the onset of general symptoms [9]. Mucous membrane involvement has been reported in a number of skin lesions, including maculopapular and vascular lesions, but not in chilblain-like lesions [6]. The dermatologic manifestations of COVID-19 infection are summarized in Table 1.

\section{Inflammatory exanthems in COVID-19 infection}

Maculopapular rashes: Maculopapular rashes appear to be the most common dermatologic manifestation of COVID-19 [5,6,8,10-12]. Among 1,847 patients with confirmed COVID-19 infection, $37.3 \%$ of patients developed maculopapular lesions that typically occurred in middle-aged females with intermediate severity of the disease [6].

The maculopapular lesions mainly involve the extremities $[6,11]$. The palms and soles are usually spared $[6,11]$. Many other studies showed that the trunk was the main involved region [11,13-16]. In an earlier study from Spain including 375 patients with COVID-19 infection, maculopapular lesions were reported in $47 \%$ of cases, itching has occurred in $57 \%$ of cases, and the lesions lasted for 8.6 (mean) days [11]. Maculopapular rashes were reported along with COVID-19 symptoms [11] and were associated with severe disease $[5,11]$. They were also reported at a late stage of the disease [17]. 


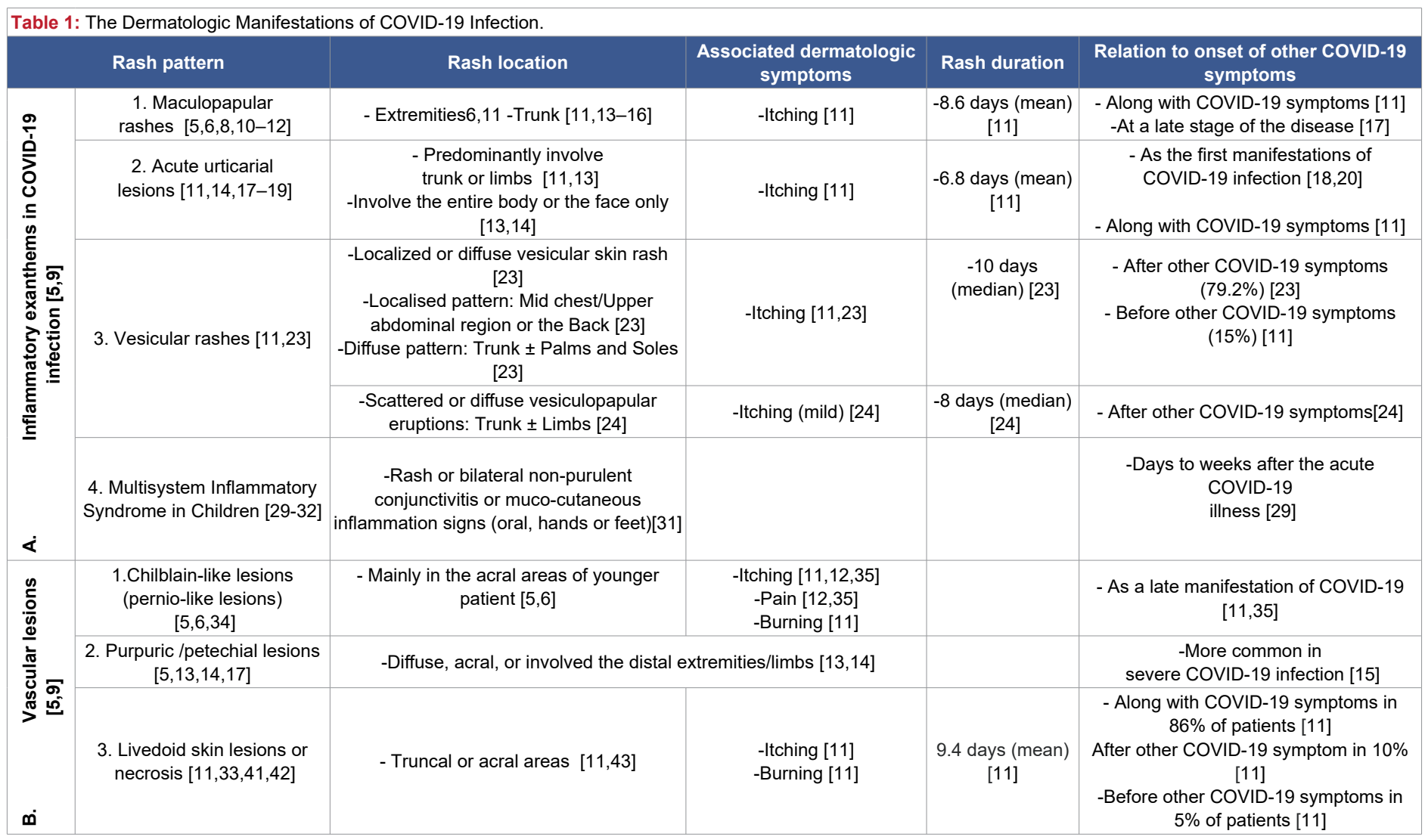

Acute urticarial lesions: Acute urticarial lesions in COVID-19 patients have also been reported [11,14,17-19]. These lesions may be concomitantly associated with fever and occurred as the first manifestations of COVID-19 infection $[18,20]$. Among 1,847 patients with confirmed COVID-19, urticarial lesions appeared as a concomitant symptom in $47 \%$ of patients [6], indicating that they may be a diagnostic sign for COVID-19 [6]. Notably, urticarial lesions have also been occurred as the first manifestations of COVID-19 infection before the onset of fever or other systemic symptoms of COVID-19 [21]. They have also been occurred at the same time as other symptoms and were associated with more severe COVID-19 with an average duration (mean) of 6.8 days [11].

Many of the urticarial rashes were located on the trunk or limbs $[11,13]$. However, the rash may be involved the entire body or only involves the face $[13,14]$. Itching was very common for urticariform lesions (92\%) [11]. The likely etiology of urticarial rashes in SARS-CoV-2 patients may be drug-induced, viral RNA induced, or a combination of both [22]. Infection-associated reactivation or exacerbation of preexisting urticaria may also be possible [22].

Vesicular rashes: Vesicular rashes are also reported in COVID-19 patients [5,23-25]. In a study from Spain, including 24 patients with COVID-19 who presented with localized or diffuse vesicular skin rash, most patients (79.2\%) developed skin rash after the onset of COVID-19 symptoms [23]. Itching was reported in $83.3 \%$ patients, whereas $16.7 \%$ did not have any associated symptoms [23]. A localised pattern was found in $25 \%$ of the patients [23]. This pattern was composed of monomorphic lesions ranging in size from 3 to $4 \mathrm{~mm}$ in diameter and all at the same stage of evolution [23]. Each patient was only affected in one central area, which was typically the mid-chest/upper abdominal region or the back [23]. A diffuse pattern was observed in $75 \%$ of patients [23]. It was made up of small papules, vesicles, and pustules ranging in size from 7-8 $\mathrm{mm}$ in diameter [23]. Various stages of the lesions appeared at the same time [23]. Although clustered in some places, there was a tendency for widespread distribution from the trunk, affecting more than one corporal area, including the palms and soles in two cases (11.1\%) [23]. The median duration of the skin rash was 10 days [23]. In another study from Italy including 22 patients with COVID-19, 72.7\% patients had scattered vesiculopapular eruptions while $27.3 \%$ patients had diffuse lesions [24]. Vesicles were observed in $54.5 \%$ of the patients [24]. The median duration of skin manifestations was 8 days (range, 4-15 days) [24]. Lesions typically appeared 3 days after the onset of COVID-19 symptoms and disappeared within 8 days, leaving no scarring [24]. The trunk was frequently involved, sometimes in tandem with the limbs (18.2\%) [24]. There was no evidence of facial or mucosal involvement [24]. Itching was reported by $40.9 \%$ of patients, and it was generally mild [24]. In a previous study from Spain including 375 patients with COVID-19 infection, vesicular lesions were reported in $9 \%$ of cases, appeared before other COVID-19 symptoms in 15\% of cases and were associated with intermedium severity [11]. Itching was common (68\%) [11]. 
The histologic examination of skin biopsies in some patients in both studies showed histologic findings that consistent with viral infection $[23,24]$. An Italian study suggested that vesicular eruptions may be specific to COVID-19, given that no patient in this study had been exposed to new medications in the last 15 days before eruption onset [24]. Other studies have suggested that these eruptions may be related to concomitant infection with herpes virus due to the dysfunctional immune response associated with COVID-19 [25,26]. The Herpesviridae family microarray polymerase chain reaction (PCR) from the vesicular fluid of three patients with COVID-19 has been performed to determine the etiology of the vesicular eruptions [25]. The results showed a combination of herpes simplex-1 virus, herpes simplex-6 virus, and EpsteinBarr virus in patient 1 , herpes simplex-1 virus, and herpes simplex-7 in patient 2 , and varicella zoster virus in patient 3 [25]. SARS-COV-2 polymerase chain reaction in the vesicle fluid could not simultaneously be performed, which cannot completely rule out its additional involvement [25]. However, some studies have reported that SARS-CoV-2 has never been isolated from the vesicle fluid of papulovesicular rash using reverse transcriptase PCR [27,28]. For example, Multiplex PCR for herpesvirus and real-time RT-PCR for SARS-CoV-2 from vesicle fluid was performed in four cases (4/24) and showed negative results [23].

\section{Multisystem inflammatory syndrome in children (MIS-C)}

A rare but serious complication of COVID-19 in children is MIS-C that has a presentation similar to Kawasaki disease (KD) or toxic shock syndrome, which may occur days to weeks after the acute COVID-19 illness [29]. The case definition for MIS-C has been provided by CDC and WHO [30,31]. The CDC case definition requires the child's age less than 21 years, while the WHO case definition specifies the age from 0 to 19 years [30,31]. Both definitions require fever, but the duration of fever is variable among them [30,31]. CDC case definition requires fever $>38.0^{\circ} \mathrm{C}$ for $\geq 24$ hours or a report of subjective fever lasting $\geq 24$ hours, while WHO definition requires fever $\geq 3$ days [30,31]. In addition, both definitions include elevated inflammatory markers such as erythrocyte sedimentation rate and C-reactive protein, procalcitonin, etc, at least two clinical signs of multisystem involvement, evidence of SARSCoV-2 infection, and no alternative possible diagnosis [30,31]. The CDC case definition requires evidence of clinically severe disease requiring hospitalization, while the WHO case definition does not apply [30,31]. Clinical signs of multisystem involvement, according to WHO [31] include: a) Rash or bilateral non-purulent conjunctivitis or muco-cutaneous inflammation signs (oral, hands or feet). b) Hypotension or shock. c) Features of myocardial dysfunction, pericarditis, valvulitis, or coronary abnormalities [including ECHO findings or elevated Troponin/ pro-B-type natriuretic peptide (NTproBNP)], d) Evidence of coagulopathy (by prothrombin time (PT), partial thromboplastin time (PTT), elevated d-Dimers). e) Acute gastrointestinal problems (diarrhoea, vomiting, or abdominal pain) [31].
A New York State study of 99 hospitalized pediatric MIS-C patients described a febrile hyperinflammatory syndrome with dermatologic, mucocutaneous, and gastrointestinal manifestations associated with cardiac dysfunction [32]. Nearly half of children 0 to 5 years of age with MIS-C but only $12 \%$ of the adolescents meet Kawasaki disease or atypical Kawasaki disease criteria [32]. Dermatologic or mucocutaneous manifestations including rash, conjunctivitis, swollen hands or feet, and mucosal changes were most common in children aged 0 to 5 years old (87\%) compared to adolescents (62\%) [32]. Neurologic symptoms, predominantly headache, were less common in children aged 0 to 5 years compared to adolescents (13\% versus 39\%) as well as myocarditis was less common in children aged 0 to 5 years compared to adolescents (39\% versus 73\%) [32] Approximately $80 \%$ of patients required intensive care, and the overall mortality rate was $2 \%$ [32].

A similar multisystem inflammatory syndrome in adults known as MIS-A, has been reported in many cases since June 2020 [30]. Although MIS-C and MIS-A are similar in many aspects, MIS-C is more common than MIS-A [30]. Because of immune system differences between adults and children, as well as the higher probability of underlying medical conditions in adults, severe MIS-A outcomes may be more likely [30].

\section{Vascular lesions}

Vascular lesions were the second most frequently described dermatologic manifestations in COVID-19 patients [33]. Different patterns of these lesions have been reported [33]. In a Systematic Review of 655 patients, vascular lesion patterns included chilblain-like $(n=84)$, non-necrotic purpura $(n=5)$, necrotic purpura $(n=2)$, retiform purpura $(n=15)$, livedo reticularis $(n=23)$, livedo racemosa $(n=$ $4)$, petechial rash $(n=4)$, eruptive cherry angiomas $(n=1)$, porcelain-like macules $(n=1)$, and dry gangrene $(n=7)$. The majority occurred after the onset of COVID-19 symptoms (25 out of 29 cases that specified the timeframe) [33].

Chilblain-like lesions: Chilblain-like lesions, also known as pernio-like lesions, are commonly seen in the acral areas of younger patients and are associated with less severe COVID-19 infections [5,6]. These lesions usually occur in warmer climates [5], while chilblains (pernio) lesions are usually triggered by cold exposure [34].

The increased incidence of pernio/acral-like or chilblainlike lesions, combined with the temporal correlation with viral symptoms, has caused to the term "COVID toes" [5]. The term derives from the dermatologic description in which the skin of the toes is presented as erythematous or violaceous lesions [5].

These lesions may be associated with pruritus [11,12,35], pain [12,35], and burning [11]. In a study from Spain including 20 children and adolescents with acral lesions, the clinical patterns were classified into: acral erythema 
(30\%) (Figure 1A), dactylitis (20\%) (Figure 1B), purpuric maculopapules (35\%) (Figure 1C), and mixed pattern (15\%) (Figure 1D) [36]. None of the patients had systemic manifestations of COVID-19. Both reverse transcriptasepolymerase chain reaction (RT-PCR) and serologic test results were negative for SARS-COV-2 [36]. Histologic findings of skin biopsies of 6 patients revealed the characteristics of perniosis [36]. In another large international registry-based case series of 505 patients with dermatologic manifestations associated with COVID-19 infection, chilblain-like lesions were reported in 63\% $(n=318)$ cases in the American Academy of Dermatology, International League of Dermatologic Societies, and other organizations registry, most of them were young and had mild COVID-19 infection [35]. The location of these lesions was in $84 \%$ of cases in the feet, in $5.1 \%$ of cases in the hands, and $10 \%$ of cases in the hands and feet [35].

Chilblain-like lesions could be a late manifestation of COVID-19 [11,35]. In 26\% (80 out of 318) cases in the previous registry, the chilblain-like lesions mainly occurred after the onset of other symptoms of COVID-19, and they usually lasted a median of 14 days (interquartile range, 10-21 days) [35]. Similarly, in a study of 375 patients with COVID-19 from Spain, chilblain-like lesions have occurred in 19\% (71 out of 375 ) patients [11]. In 59\% (42 out of 71) patients developed lesions after other symptoms of COVID-19 disease, while $41 \%$ (29 out of 71) developed lesions along with other symptoms of COVID-19 [11]. In some cases, chilblain-like lesions were the only presentation of COVID-19 [11,35].

The majority of the dermatologic manifestations were occurred in middle-aged females [6]. while chilblain-like lesions were more common in younger patients $[6,8,11]$ with mild and or even asymptomatic courses or negative SARSCoV-2 testing [11]. Other vascular lesions were more common in the elderly [6].
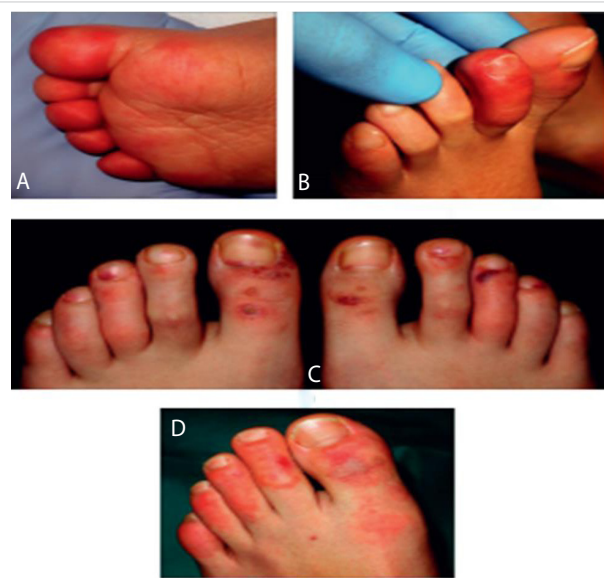

Figure 1: Details of the clinical spectrum (reused from Roca-Ginés, et al. JAMA Dermatology 2020 [36]; reference under the terms of the CC-BY license, which allows unrestricted use, distribution, and reproduction in any medium or format with acknowledgment of the original source). A: Acral erythema pattern on the dorsal side of the toes. B: Inflammation of 1 toe showing a dactylitis pattern. C: Moderate vasculiticlike lesions on the feet demonstrating a maculopapular purpuric pattern. D: Mixed pattern composed of dactylitis and purpuric maculopapules.
The typical histopathologic features of chilblain-like lesions include superficial and deeper lymphocytic infiltration in the lichenoid, perivascular and perieccrine patterns, with occasional plasma cells, and mild vacuolar degeneration of the basal layer of the epidermis [27,37-39]. Exocytosis of lymphocytes and occasional necrotic keratinocytes in the superficial layers of the epidermis can be observed [27,37-39]. Indirect features of vascular damage such as extravasation of erythrocytes and dermal oedema were identified [27,37-39].

Variable degrees of lymphocytic vasculitis ranging from endothelial swelling and endotheliitis to fibrinoid necrosis and thrombosis have also been observed [27]. These thrombi involved the papillary dermal capillaries and involved reticular dermis vessels [27].

Cytoplasmic granular positivity for SARS-CoV-2 spike protein in endothelial cells of the capillary and post-capillary venules of the upper dermis, and in epithelial cells of the secretory portion of eccrine units were identified in a small series of pediatric patients [27].

The exact pathophysiological mechanisms leading to chilblain-like lesions or vascular lesions are not completely understood. Patients with severe COVID- 19 are at risk of coagulopathy and subsequent thrombotic events [6,13]. Microvascular thrombosis of dermal vessels leading to ischemia or vasculitis has been observed in chilblain-like or vascular lesions $[6,13]$. These findings as well as significant increases in D-dimer levels and changes in coagulation parameters such as an increase in PT, international normalized ratio (INR), and fibrinogen in patients with chilblain-like and vascular lesions supported this hypothesis [6].

It also has been hypothesized that in young patients, a robust antiviral type I interferon response suppresses early viral replication and induces microangiopathic changes, resulting in chilblain lupus erythematosus-like eruption, while in older patients, insufficient or delayed interferon-1 response exacerbates pre-existing cytokine storms, leading to increased morbidity and mortality [37]. Similarly, other studies have shown that chilblain-like lesions have occurred in younger patients at the late stage of COVID-19 and have been associated with a mild disease course $[11,35]$.

Another hypothesis suggested that endothelial damage caused by SARS-CoV-2 may have a role in the pathogenesis of COVID-19 chilblains [27,39]. SARS-CoV-2 has been demonstrated in endothelial cells of skin biopsies by immunohistochemistry and electron microscopy in a small number of pediatric patients with COVID-19 [27].

On the contrary, other hypotheses have suggested that chilblain is not directly related to COVID-19 infection based on the negativity of reverse transcriptase-polymerase chain reaction in nasopharyngeal swabs and negativity of anti-SARSCoV-2 serology tests $[36,40]$. Thus, lifestyle changes related to 
community containment and lockdown measures may explain these lesions [40]. Of note, most of these hypotheses are based on studies that have been performed in a limited number of patients, so more studies are needed to validate them.

\section{Purpuric/petechial lesions}

Hemorrhagic events and subsequent dermatologic manifestations such as petechiae, purpura, and livedo are another manifestation of coagulopathy in COVID-19 patients [6]. Thrombocytopenia, systemic lupus erythematosus, leukaemia, disseminated intravascular coagulation, hemolytic uremic syndrome, thrombotic thrombocytopenic purpura, vasculitis, and vitamin $\mathrm{C}$ deficiency have all been suggested as potential causes of purpuric/petechial lesions [5].

Purpuric and petechial lesions may be diffuse, acral, or involve the distal extremities/limbs $[13,14]$. Diffuse petechiae and generalised palpable purpura were more common in cases of severe COVID-19 infection [15]. In a study of 34 COVID-19 patients with confirmed or suspected infection, palpable purpuric lesions were reported in four patients (11.8\%), two of whom had palpable purpura lesions as well as an atypical polymorphic papulovesicular eruption and one of whom had an urticarial exanthem [17]. These lesions were more common in middle-aged patients during recovery from severe COVID-19 [17].

Livedoid skin lesions: Livedoid skin lesions or necrosis have also been reported in a few patients with COVID-19 [11,33,41,42]. In a study of 375 patients with COVID-19, these vascular lesions were observed in $6 \%$ of patients with an average duration (mean) of 9.4 days [11]. Itching, burning and pain have been reported in $14 \%, 10 \%$, and 5\%, respectively [11]. Livedoid skin lesions or necrosis have appeared with other symptoms of COVID-19 in $86 \%$ of patients while appearing late during the disease in $10 \%$ and appeared before other symptoms in $5 \%$ of patients [11]. Different degrees of these lesions, suggesting the occlusive vascular disease, including areas of truncal or acral ischemia, have been reported [11]. Severe COVID-19 may be associated with vascular damage and alterations in coagulation status [43]. Of note, livedoid skin lesions or necrotic lesions mainly occurred in elderly patients with the more severe COVID-19 disease, associated with the highest rate of mortality [11].

In the report of five cases with COVID-19 and severe respiratory failure, three of them also had retiform purpura or livedo racemos, histologic and immunohistochemistry studies of pulmonary and dermatologic biopsies showed microvascular injury and thrombosis, accompanied by the severe complement activation [42]. Pauci-inflammatory complement-induced microthrombotic disease with C5b-9 and C4d deposition in samples obtained from both dermatologic lesions and normal-looking skin has been demonstrated [42].

\section{Ophthalmological features of the COVID-19}

Ophthalmological manifestations in patients with COVID-19 are also reported [33,44,45]. Conjunctivitis is the most common reported ocular manifestation of this disease $[33,44,45]$. In a study of 38 patients with confirmed COVID-19 infection, one-third of patients had ophthalmologic manifestations, such as conjunctival hyperemia, chemosis, epiphora, or increased secretion, and these frequently occurred in patients with more severe COVID-19 [45]. In a systemic review of 655 patients with COVID-19, eleven patients had conjunctivitis, one patient had eyelid dermatitis and conjunctivitis, and two patients had eyelid dermatitis [33].

Conjunctivitis can be the first and only symptom of the disease [44]. Of note, among the 38 patients with confirmed COVID-19 infection, SARS-CoV-2 was detected by RT-PCR in tear samples of two patients [45]. Similarly, in another study of 121 Patients with confirmed COVID-19, SARS-CoV-2 was detected by RT-PCR in the conjunctival swabs of three patients [46]. This could point to the possibility of SARS-CoV-2 transmission through the eyes $[45,46]$. As a result, healthcare workers, particularly ophthalmologists, who perform examinations without wearing eye goggles while close to COVID-19 patients may be at risk of COVID-19 infection due to ocular exposure [46]. Therefore, when examining patients with features of viral conjunctivitis, proper precautions of eye protection should be taken $[44,46]$.

The retina can also be affected in COVID-19 patients. In a study describing the optical coherence tomography (OCT) findings in twelve patients; nine of them had SARS-CoV-2 positivity of nasal and oral swabs via PCR and two patients had anti-SARS-CoV-2 positivity, hyperreflective lesions at the level of ganglion cell and inner plexiform layers more prominently at the papillomacular bundle in both eyes were observed in all patients [47]. Additionally, subtle cotton wool spots and microhemorrhages along the retinal arcade were observed on fundus examination, color fundus photography, and red-free imaging in four patients [47].

\section{Conclusion}

COVID-19 can cause several extrapulmonary manifestations including dermatologic manifestations. These manifestations include maculopapular rash, vesicular lesions, urticaria-like lesions, and chilblain-like lesions. Knowledge of dermatologic manifestations associated with COVID-19 may be vital to early diagnosis and lead to possible better prognosis in COVID-19 patients..

Authors' contributions: The author read and approved the final version of the manuscript.

\section{References}

1. WHO Director-General's opening remarks at the media briefing on 
COVID-19 - 11 March 2020. WHO Director General's speeches 2020. https://www.who.int/director-general/speeches/detail/who-directorgeneral-s-opening-remarks-at-the-media-briefing-on-covid-19---11march-2020 .

2. Wong $\mathrm{CKH}$, Wong JYH, Tang EHM, et al. Clinical presentations, laboratory and radiological findings, and treatments for 11,028 COVID-19 patients: a systematic review and meta-analysis. Sci Rep. 2020; 10: 19765.

3. da Rosa Mesquita R, Francelino Silva Junior LC, Santos Santana FM, de Oliveira TF, Alcântara RC, et al. Clinical manifestations of COVID-19 in the general population: systematic review. Wien Klin Wochenschr. 2021: 133: 377-382.

PubMed: https://pubmed.ncbi.nlm.nih.gov/33242148/

4. Johnson KD, Harris C, Cain JK, Hummer C, Goyal H, et al. Pulmonary and Extra-Pulmonary Clinical Manifestations of COVID-19. Front Med. 2020; 7: 526.

PubMed: https://pubmed.ncbi.nlm.nih.gov/32903492/

5. Singh $\mathrm{H}$, Kaur $\mathrm{H}$, Singh $\mathrm{K}$, Sen $\mathrm{CK}$. Cutaneous Manifestations of COVID-19: A Systematic Review. Adv Wound Care. 2021; 10: 51-80. PubMed: https://pubmed.ncbi.nlm.nih.gov/33035150/

6. Jamshidi P, Hajikhani B, Mirsaeidi M, Vahidnezhad H, Dadashi M, et al. Skin Manifestations in COVID-19 Patients: Are They Indicators for Disease Severity? A Systematic Review. Front Med. 2021; 8: 634208. PubMed: https://pubmed.ncbi.nlm.nih.gov/33665200/

7. Guan W, Ni Z, Hu Y, et al. Clinical Characteristics of Coronavirus Disease 2019 in China. N Engl J Med. 2020; 382: 1708-1720.

8. Recalcati S. Cutaneous manifestation in COVID-19: a first perspective. J Eur Acad Dermatol Venereol. 2020; 34: e212-e213. PubMed: https://pubmed.ncbi.nlm.nih.gov/32215952/

9. Klejtman T. Skin and COVID-19. JMV-Journal Médecine Vasc. 2020; 45: $175-176$

10. Sachdeva M, Gianotti R, Shah M, Bradanini L, Tosi D, et al. Cutaneous manifestations of COVID-19: Report of three cases and a review of literature. J Dermatol Sci. 2020; 98: 75-81.

PubMed: https://pubmed.ncbi.nlm.nih.gov/32381430/

11. Galván Casas C, Català A, Carretero Hernández G, RodríguezJiménez $P$, Fernández-Nieto $D$, et al. Classification of the cutaneous manifestations of COVID-19: a rapid prospective nationwide consensus study in Spain with 375 cases. Br J Dermatol. 2020; 183: 71-77. PubMed: https://pubmed.ncbi.nlm.nih.gov/32348545/

12. Najarian DJ. Morbilliform exanthem associated with COVID-19. JAAD Case Rep. 2020; 6: 493-494.

PubMed: https://pubmed.ncbi.nlm.nih.gov/32313826/

13. de Masson A, Bouaziz JD, Sulimovic L, Cassius C, Jachiet M, et al. Chilblains is a common cutaneous finding during the COVID-19 pandemic: A retrospective nationwide study from France. J Am Acad Dermatol. 2020; 83: 667-670.

PubMed: https://pubmed.ncbi.nlm.nih.gov/32380219/

14. Askin O, Altunkalem RN, Altinisik DD, Uzuncakmak TK, Tursen U, et al. Cutaneous manifestations in hospitalized patients diagnosed as COVID-19. Dermatol Ther 2020; 33: e13896.

PubMed: https://pubmed.ncbi.nlm.nih.gov/32579756/

15. De Giorgi V, Recalcati S, Jia Z, Chong W, Ding R, et al. Cutaneous manifestations related to coronavirus disease 2019 (COVID-19): A prospective study from China and Italy. J Am Acad Dermatol. 2020; 83: 674-675.

PubMed: https://pubmed.ncbi.nlm.nih.gov/32442696/

16. Herrero-Moyano M, Capusan TM, Andreu-Barasoain M, AlcántaraGonzález J, Ruano-Del Salado M, et al. A clinicopathological study of eight patients with COVID-19 pneumonia and a late-onset exanthema. J Eur Acad Dermatol Venereol. 2020; 34: e460-e464. PubMed: https://pubmed.ncbi.nlm.nih.gov/32426864/
17. Rubio-Muniz CA, Puerta-Peña M, Falkenhain-López D, ArroyoAndrés $\mathrm{J}$, Agud-Dios $\mathrm{M}$, et al. The broad spectrum of dermatological manifestations in COVID-19: clinical and histopathological features learned from a series of 34 cases. J Eur Acad Dermatol Venereol. 2020; 34: e574-e576.

PubMed: https://pubmed.ncbi.nlm.nih.gov/32526040/

18. Damme C, Berlingin E, Saussez S, Accaputo O. Acute urticaria with pyrexia as the first manifestations of a COVID-19 infection. J Eur Acad Dermatol Venereol. 2020; 34: e300-e301.

PubMed: https://pubmed.ncbi.nlm.nih.gov/32329915/

19. Estébanez A, Pérez-Santiago L, Silva E, Guillen-Climent S, GarcíaVázquez $\mathrm{A}$, et al. Cutaneous manifestations in COVID-19: a new contribution. J Eur Acad Dermatol Venereol. 2020; 34: e250-e251. PubMed: https://pubmed.ncbi.nlm.nih.gov/32294264/

20. Amatore F, Macagno N, Mailhe M, Demarez B, Gaudy-Marqueste C et al. SARS-CoV-2 infection presenting as a febrile rash. J Eur Acad Dermatol Venereol 2020; 34: e304-e306.

PubMed: https://pubmed.ncbi.nlm.nih.gov/32330336/

21. HenryD,AckermanM,SancelmeE,FinonA,EsteveE. Urticarialeruptionin COVID-19 infection. JEur Acad Dermatol Venereol 2020; 34: e244-e245. PubMed: https://pubmed.ncbi.nlm.nih.gov/32294273/

22. Novak N, Peng W, Naegeli MC, et al. SARS-CoV-2, COVID-19, skin and immunology - What do we know so far? Allergy. 2021; 76: 698-713.

23. Fernandez-Nieto D, Ortega-Quijano D, Jimenez-Cauhe J, BurgosBlasco P, de Perosanz-Lobo D, et al. Clinical and histological characterization of vesicular COVID-19 rashes: a prospective study in a tertiary care hospital. Clin Exp Dermatol. 2020; 45: 872-875. PubMed: https://pubmed.ncbi.nlm.nih.gov/32384180/

24. Marzano AV, Genovese G, Fabbrocini G, Pigatto P, Monfrecola G, et al. Varicella-like exanthem as a specific COVID-19-associated skin manifestation: Multicenter case series of 22 patients. J Am Acad Dermatol. 2020; 83: 280-285.

PubMed: https://pubmed.ncbi.nlm.nih.gov/32305439/

25. Llamas-Velasco $M$, Rodríguez-Jiménez $P$, Chicharro $P$, De Argila $D$, Muñoz-Hernández $P$, et al. Reply to "Varicella-like exanthem as a specific COVID-19-associated skin manifestation: Multicenter case series of 22 patients": To consider varicella-like exanthem associated with COVID-19, virus varicella zoster and virus herpes simplex must be ruled ou. J Am Acad Dermatol. 2020; 83: e253-e254. PubMed: https://pubmed.ncbi.nlm.nih.gov/32442700/

26. Marzano AV, Genovese G. Response to: "Reply to "Varicella-like exanthem as a specific COVID-19-associated skin manifestation: multicenter case series of 22 patients": To consider varicella-like exanthem associated with COVID-19, virus varicella zoster and virus herpes simplex mu. J Am Acad Dermatol. 2020; 83: e255-e256.

27. Colmenero I, Santonja C, Alonso-Riaño M, Noguera-Morel L, Hernández-Martín A, et al. SARS-CoV-2 endothelial infection causes COVID-19 chilblains: histopathological, immunohistochemical and ultrastructural study of seven paediatric cases. $\mathrm{Br} \mathrm{J}$ Dermatol. 2020; 183: $729-737$

PubMed: https://pubmed.ncbi.nlm.nih.gov/32562567/

28. Trellu LT, Kaya G, Alberto C, Calame A, McKee T, et al. Clinicopathologic Aspects of a Papulovesicular Eruption in a Patient With COVID-19. JAMA Dermatol. 2020; 156: 922-924.

PubMed: https://pubmed.ncbi.nlm.nih.gov/32579185/

29. Jones VG, Mills M, Suarez D, Hogan CA, Yeh D, et al. COVID-19 and Kawasaki Disease: Novel Virus and Novel Case. Hosp Pediatr 2020; 10: $537-540$.

PubMed: https://pubmed.ncbi.nlm.nih.gov/32265235/

30. Center for Disease Control and Prevention. Information for Healthcare Providers about Multisystem Inflammatory Syndrome in Children (MIS-C). CDC. 2021.

PubMed: https://www.cdc.gov/mis-c/hcp/ 
31. World Health Organization. Multisystem inflammatory syndrome in children and adolescents temporally related to COVID-19: Scientific Brief 15 May 2020. WHO. 2020; 1-9. https://www.who.int/news-room/ commentaries/detail/multisystem-inflammatory-syndrome-in-childrenand-adolescents-with-covid-19

32. Dufort EM, Koumans EH, Chow EJ. Multisystem Inflammatory Syndrome in Children in New York State. N Engl J Med. 2020; 383: 347-358.

33. Conforti C, Dianzani C, Agozzino M, Giuffrida R, Marangi GF, et al Cutaneous Manifestations in Confirmed COVID-19 Patients: A Systematic Review. Biology (Basel). 2020; 9: 449.

PubMed: https://pubmed.ncbi.nlm.nih.gov/33291502/

34. Cappel JA, Wetter DA. Clinical characteristics, etiologic associations, laboratory findings, treatment, and proposal of diagnostic criteria of pernio (chilblains) in a series of 104 patients at Mayo Clinic, 2000 to 2011. Mayo Clin Proc. 2014; 89: 207-215.

PubMed: https://pubmed.ncbi.nlm.nih.gov/24485134/

35. Freeman EE, McMahon DE, Lipoff JB, Rosenbach M, Kovarik C, et al. Pernio-like skin lesions associated with COVID-19: A case series of 318 patients from 8 countries. J Am Acad Dermatol. 2020; 83: 486-492. PubMed: https://pubmed.ncbi.nlm.nih.gov/32479979/

36. Roca-Ginés J, Torres-Navarro I, Sánchez-Arráez J, Abril-Pérez C Sabalza-Baztán O, et al. Assessment of Acute Acral Lesions in a Case Series of Children and Adolescents During the COVID-19 Pandemic. JAMA Dermatol. 2020; 156: 992-997.

PubMed: https://pubmed.ncbi.nlm.nih.gov/32584397/

37. Kolivras A, Dehavay F, Delplace D, Feoli F, Meiers I, et al. Coronavirus (COVID-19) infection-induced chilblains: A case report with histopathologic findings. JAAD Case Rep. 2020; 6: 489-492.

PubMed: https://pubmed.ncbi.nlm.nih.gov/32363225/

38. Locatelli AG, Robustelli Test E, Vezzoli P, Carugno A, Moggio E, et al. Histologic features of long-lasting chilblain-like lesions in a paediatric COVID-19 patient. J Eur Acad Dermatol Venereol. 2020; 34 : e365-e368.

PubMed: https://pubmed.ncbi.nlm.nih.gov/32386459/

39. Santonja C, Heras F, Núñez L, Requena L. COVID-19 chilblain-like lesion: immunohistochemical demonstration of SARS-CoV-2 spike protein in blood vessel endothelium and sweat gland epithelium in a polymerase chain reaction-negative patient. Br J Dermatol. 2020; 183: 778-780.

PubMed: https://pubmed.ncbi.nlm.nih.gov/32585767/

40. Herman A, Peeters C, Verroken A, Tromme I, Tromme I, Tennstedt D, et al. Evaluation of Chilblains as a Manifestation of the COVID-19 Pandemic. JAMA Dermatol. 2020; 156: 998-1003. PubMed: https://pubmed.ncbi.nlm.nih.gov/32584377/

41. Marzano AV, Cassano N, Genovese G, Moltrasio C, Vena GA, et al Cutaneous manifestations in patients with COVID-19: a preliminary review of an emerging issue. $\mathrm{Br} J$ Dermatol. 2020; 183: 431-442. PubMed: https://pubmed.ncbi.nIm.nih.gov/32479680/

42. Magro C, Mulvey JJ, Berlin D, Nuovo G, Salvatore S, et al. Complement associated microvascular injury and thrombosis in the pathogenesis of severe COVID-19 infection: A report of five cases. Transl Res. 2020; 220: 1-13. PubMed: https://pubmed.ncbi.nlm.nih.gov/32299776/

43. Tang N, Li D, Wang X, Sun Z. Abnormal coagulation parameters are associated with poor prognosis in patients with novel coronavirus pneumonia. J Thromb Haemost. 2020; 18: 844-847. PubMed: https:// pubmed.ncbi.nlm.nih.gov/32073213/

44. Bertoli F, Veritti D, Danese C. Ocular Findings in COVID-19 Patients: A Review of Direct Manifestations and Indirect Effects on the Eye. J Ophthalmol. 2020; 2020: 1-9.

45. Wu P, Duan F, Luo C, Liu Q, Qu X, et al. Characteristics of Ocular Findings of Patients With Coronavirus Disease 2019 (COVID-19) in Hubei Province, China. JAMA Ophthalmol. 2020; 138: 575-578. PubMed: https://pubmed.ncbi.nlm.nih.gov/32232433/

46. Zhou $Y$, Duan $C$, Zeng $Y$, Tong $Y$, Nie $Y$, et al. Ocular Findings and Proportion with Conjunctival SARS-COV-2 in COVID-19 Patients. Ophthalmol. 2020; 127: 982-983. PubMed: https://pubmed.ncbi.nlm. nih.gov/32359840/

47. Marinho PM, Marcos AAA, Romano AC, Nascimento H, Belfort R SJr. Retinal findings in patients with COVID-19. Lancet. 2020; 395: 1610. PubMed: https://pubmed.ncbi.nlm.nih.gov/32405105/ 